\title{
DYNAMICS OF THERMOELASTIC PLATE SYSTEM WITH TERMS CONCENTRATED IN THE BOUNDARY
}

\author{
Gleiciane S. Aragão, Flank D. M. Bezerra and Cládio O. P. Da Silva
}

Abstract. In this paper we show the existence, uniform boundedness and upper semicontinuity of the global attractors of autonomous thermoelastic plate systems with Neumann boundary conditions when some reaction terms are concentrated in a neighborhood of the boundary and this neighborhood shrinks to boundary as a parameter $\varepsilon$ goes to zero.

Mathematics subject classification (2010): 35A01, 35B40, 35B41, 37L05.

Keywords and phrases: Global attractor, thermoelastic plate systems, autonomous, concentrating terms, upper semicontinuity.

\section{REFERENCES}

[1] H. Amann, Linear and Quasilinear Parabolic Problems. Volume I: Abstract Linear Theory, Birkhäuser Verlag, Basel, 1995.

[2] G. S. AragÃo AND F. D. M. BeZerRA, Upper semicontinuity of the pullback attractors of nonautonomous damped wave equations with terms concentrating on the boundary, Messenger Math., 462, (2018), 871-899.

[3] G. S. Aragão AND F. D. M. Bezerra, Continuity of the set equilibria of non-autonomous damped wave equations with terms concentrating on the boundary, Electronic Journal of Differential Equations 702019 (2019), 1-19.

[4] G. S. ARAGÃo AND S. M. Oliva, Delay nonlinear boundary conditions as limit of reactions concentrating in the boundary, J. Differential Equations 253 (2012), no. 9, 2573-2592.

[5] G. S. ARAgÃo AND S. M. Oliva, Asymptotic behavior of a reaction-diffusion problem with delay and reaction term concentrated in the boundary, São Paulo Journal of Mathematical Sciences, 5 (2011), no. 2, 347-376.

[6] G. S. Aragão, A. L. Pereira and M. C. Pereira, A nonlinear elliptic problem with terms concentrating in the boundary, Mathematical Methods in the Applied Sciences, 35 (2012) 1110-1116.

[7] G. S. Aragão, A. L. Pereira And M. C. Pereira, Attractors for a nonlinear parabolic problem with terms concentrating in the boundary, J. of Dynamics and Differential Equations 26 (4) (2014) 871-888.

[8] J. M. Arrieta, A. N. Carvalho and A. Rodríguez-Bernal, Attractors of parabolic problems with nonlinear boundary conditions. Uniform bounds, Communications in Partial Differential Equations 25 (1-2) (2000) 1-37.

[9] J. M. ARrieta, A. Jiménez-Casas And A. RodríGueZ-Bernal, Flux terms and Robin boundary conditions as limit of reactions and potentials concentrating at the boundary, Rev. Iberoam. Mat. 24 (1) (2008) 183-211.

[10] M. Baroun, S. Boulite, T. Diagana, And L. Maniar, Almost periodic solutions to some semilinear non-autonomous thermoelastic plate equations, J. Math. Anal. Appl. 349 (2009) 74-84.

[11] F. D. M. Bezerra, V. L. CArbone, M. J. D. Nascimento and K. Schiabel, Pullback attractors for a class of non-autonomous thermoelastic plate systems, Discrete \& Continuous Dynamical Systems, (2018) 23(9): 3553-3571.

[12] A. N. CARVAlHo, J. W. ChOLEWA, Local well-posedness for strongly damped wave equations with critical nonlinearities, Bull. Austral. Math. Soc. 66 (2002) 443-463. 
[13] J. Cholewa And T. DŁotko, Global Attractors in Abstract parabolic Problem, London Mathematical Society Lecture Note Series, 278. Silesian University, Poland.

[14] A. JimÉnEZ-CASAS AND A. RodríGUEZ-BERnAL, Aymptotic behaviour of a parabolic problem with terms concentrated in the boundary, Nonlinear Analysis: Theory, Methods \& Applications $\mathbf{7 1}$ (2009), 2377-2383.

[15] A. JIMÉNEZ-CASAS AND A. RodRíGUEZ-BERnAL, Singular limit for a nonlinear parabolic equation with terms concentrating on the boundary, J. Math. Anal. Appl. 379 (2) (2011) 567-588.

[16] J. K. Hale, Asymptotic Behavior of Dissipative System, Lecture Notes in Mathematics, American Mathematical Society, Mathematical Surveys and Monographs, 25, Springer-Verlag, New York, 1988.

[17] D. Henry, Geometric Theory of Semilinear Parabolic Equations, Lecture notes in Mathematics. Springer-Verlag. Berlin Heidelberg New York 1981.

[18] I. LASIECKA AND R. TRIGGIANI, Analyticity of thermo-elastic semigroups with free boundary conditions, Ann. Sc. Norm. Super. Pisa Cl. Sci. 27(1998), 457-482.

[19] Z. Y. LiU AND M. RenARdy, A note on the equations of a thermoelastic plate, Appl. Math. Lett. 8(3) (1995), 1-6.

[20] Z. LIU AND S. ZHENG, Semigroups associated with dissipative systems, In CRC Research Notes in Mathematics 398, Chapman and Hall, 1999.

[21] M. C. Pereira, Remarks on Semilinear Parabolic Systems with terms concentrating in the boundary, Nonlinear Anal. Series B: Real World Applications, 144 (2013) 1921-1930.

[22] H. TRIEBEL, Interpolation theory, function spaces, differential operators, NH Publishing Company, Amsterdan, New York, Oxford, 1978. 